\title{
Effect of Holding Time and Cooling Medium on Microstructure and Hardness of AISI 8655 in
} Hardening Process

\author{
Alvian Toto Wibisono ${ }^{1}$, Mavindra Ramadhani ${ }^{1}$, Rochman Rochiem ${ }^{1}$
}

\begin{abstract}
The microstructure transformation of AISI 8655, affecting to hardness and impact properties in various hardening processes, has been investigated in this work. AISI 8655 specimens which had been prepared before hardening processes were heated to austenite temperature and held for 30 minutes and 60 minutes then continued by rapid cooling in various medium (air, oil and water). The hardened steel specimens were tested by optical microscope to observe microstructure, brinell test and impact test respectively to measure hardness and impact strength properties. Martensite and bainite were microstructures that appeared after hardening processes. The holding time for $\mathbf{3 0}$ minutes gave higher hardness properties than the holding time for 60 minutes. However, the holding time for 60 minutes performed higher impact strength than that for 30 minutes. The highest of hardness was performed by the specimen cooled in water medium at 552 BHN and the highest of impact strength was performed by the specimen cooled in air medium at $7.2 \mathrm{~J} / \mathrm{mm} 2$.
\end{abstract}

Keywords_-AISI 8655, Hardening, Holding Time, Cooling Medium

\section{INTRODUCTION}

A ISI 8655, hypo-eutectoid low alloys medium steel, are widely used as a hummer crusher component in cement industry due to its machinability, strength, toughness, hardness and impact strength [1]. The failure analysis which had been performed in previous study showed the factor caused the failure of this component. Low abrasion resistance correspond to low hardness properties is the factor caused component's failure. Moreover, to prevent the failure, microstructure and properties of AISI 8655 have to improve by hardening process.

Microstructure of hypoeutectic low alloys steel consist of ferrite-pearlite that can be hardened by transforming them to martensite [2]. Some parameters used in hardening process are austenite temperature, holding time, cooling process (isothermal cooling and continous cooling), cooling rate, and cooling medium. To transform ferritepearlite in hypo-eutectoid low alloys carbon steel, the steel is heated into austenite temperature above A3 line then held until homogeneous austenite is occur then continued by rapid cooling [3]. Various cooling mediums used in hardening process are air, oil, water and brine (salted water) whose have difference in grossmann factor value. Brine (2.0 grossmann factor value) give the highest hardness Enhancement compared with water (0.9 - 1 grossmann factor value) and oil (0.25-0.3 grossmann factor value) [3]. Enhancement of heating temperature then cooling via water medium during hardening process upgrades hardness of hypo-eutectoid medium carbon steel [4]. Martensite as a stress carrying has plays a significant role on performance of low alloys carbon steels and therefore its associated properties are at the immense importance. Martensite is usually assumed as a single homogeneous phase which is formed by critical cooling rate in quenching medium [5].
Martensite has heterogeneity in its micromechanical strength and importantly the following consequences on final mechanical properties [6].

In spite of all the dedicated effort on the correlation between microstructure evolution and mechanical properties of low alloys carbon steel in hardening process, the exclusive effect of hardening to AISI 8655 not yet investigated schematically. Therefore, the objective of this paper is to directly exhibit the result of experimental observation from study of microstructure and hardness evolution in hardening process.

TABLE 1.

Chemical Composition of OBSERVED SteEl Alloy (WT\%)

\begin{tabular}{ccccccccc}
\hline \hline C & Si & Mn & P & S & Ni & Mo & Cr & Fe \\
\hline 0.5 & 0.3 & 0.7 & 0.0 & 0.0 & 0.3 & 0.2 & 1.9 & Balanc \\
9 & 7 & 7 & 2 & 1 & 9 & 3 & 1 & $\mathrm{e}$ \\
\hline \hline
\end{tabular}

\section{METHOD}

\section{A. Material and experimental procedures}

The chemical composition of investigated AISI 8655 is given in Table 1. AISI 8655 was obtained from PT. Semen Indonesia Tuban. The material has been cut into specimens with each final dimension of $10 \times 10 \times 60 \mathrm{~mm}^{3}$. The specimens were hardened by method that showed in Figure 1 . The specimens were heated in a muffle furnace to $850^{\circ} \mathrm{C}$ and held for 30 minutes and 60 minutes. The heated specimens were quenched by various medium: air, oil and water until carried room temperature. Grinding papers of grit size P240, P360, P500, P800, P1000, P1500 and P2000 $\mathrm{SiC}$ to prepare metal alloys surface for metallography were purchased by Santo. Nitric acid (65\%), methanol (95\%) and distilled water were purchased by Merck Sigma Aldrich as etchant materials. Unsaturated Polyester resin and hardener were purcashed by Yukalac and suspension of Alumina was purchased by Kasel.

\footnotetext{
${ }^{1}$ Alvian Toto Wibisono, Mavindra Ramadhani and Rochman Rochiem are with Department of Material Engineering, ITS, Surabaya, 60111, Indonesia, alviantotow@gmail.com
} 


\section{B. Metallography}

Microstructure transformation of observed steel and hardened specimens are analyzed by metallography method. All of specimens were prepared by ASTM E3 method. Specimens cut into final dimension of $10 \mathrm{x} 10 \mathrm{x}$ $10 \mathrm{~mm}^{3}$. Mixing of unsaturated polyester resin and hardener at weight ratio 10:1 was used as castable mounts. The specimens whose one side surface were protected by plester tape were placed into cup molds. The mixing mount was poured into each molds and it was cured for 24 hours. The mounted specimens were separated with the molds and plester tape. Grinding process to make flat size P240 to P2000 SiC. Then suspension of alumina was used as polishing material to get final flat surface specimens. All of specimens were etched by ASTM E407 method. Nital, chemical solutions used in etching specimens, was made from $5 \mathrm{~mL}$ nitric acid and $100 \mathrm{~mL}$ methanol. The prepared flat surface of specimens was immersed into nital for 20 seconds. Microstructure of each specimens was performed by employing a Olympus BX41 optical microscope.

\section{Hardness Test}

Brinell hardness number of specimens was measured by ASTM E10 method. Universal hardness tester Wolpert

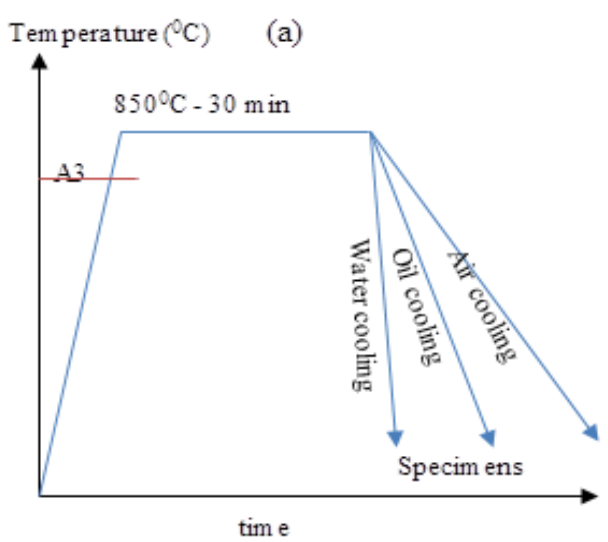

Wilson Instrument Testor 930 was used to perform hardness measurement. Specimen surface was prepared by grinding until grit $1200 \mathrm{SiC}$ paper before testing. The applied load was $25 \mathrm{gr}$ and dwelling time of indenter was 10 seconds. A total of 5 indentations were applied for each specimen. Distance between indentation point was kept at least $100 \mu \mathrm{m}$. The hardness of each specimens reported in this paper is average hardness of 5 measurements.

\section{Impact Test}

Impact strength of specimens was measured by ASTM E23 method. Impact tester machine IT-30 was used to perform impact strength measurement. Specimens with dimension $10 \times 10 \times 50 \mathrm{~mm}^{3}$ were prepared for charpy model. A V-notch of each specimens was placed in center of the specimen as deep $2 \mathrm{~mm}$ and formed angle of 45 degree. The pendulum applied load was $450 \mathrm{~kg}$ freely strike from back of the specimen. The impact surface of specimens was done by grinding paper of grit strength of each specimens reported in this paper is average impact of 3 measurements.

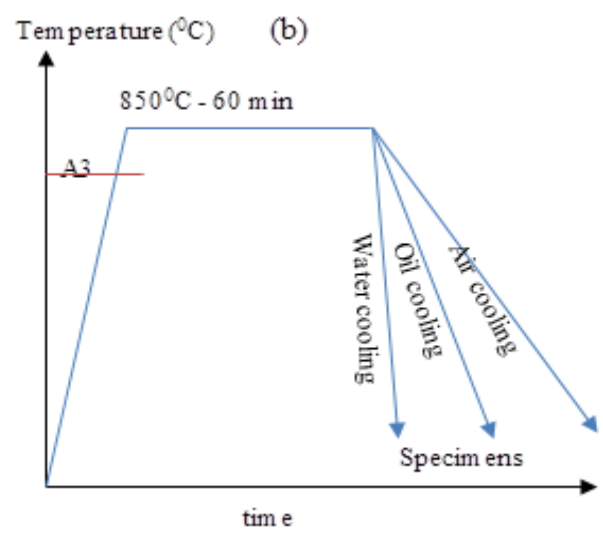

Figure 1. Schematic of hardening process (a) heating at $850^{\circ} \mathrm{C}$ holding for 30 minutes and cooling in various medium (b) heating at $850^{\circ} \mathrm{C}$ holding for 60 minutes and cooling in various medium

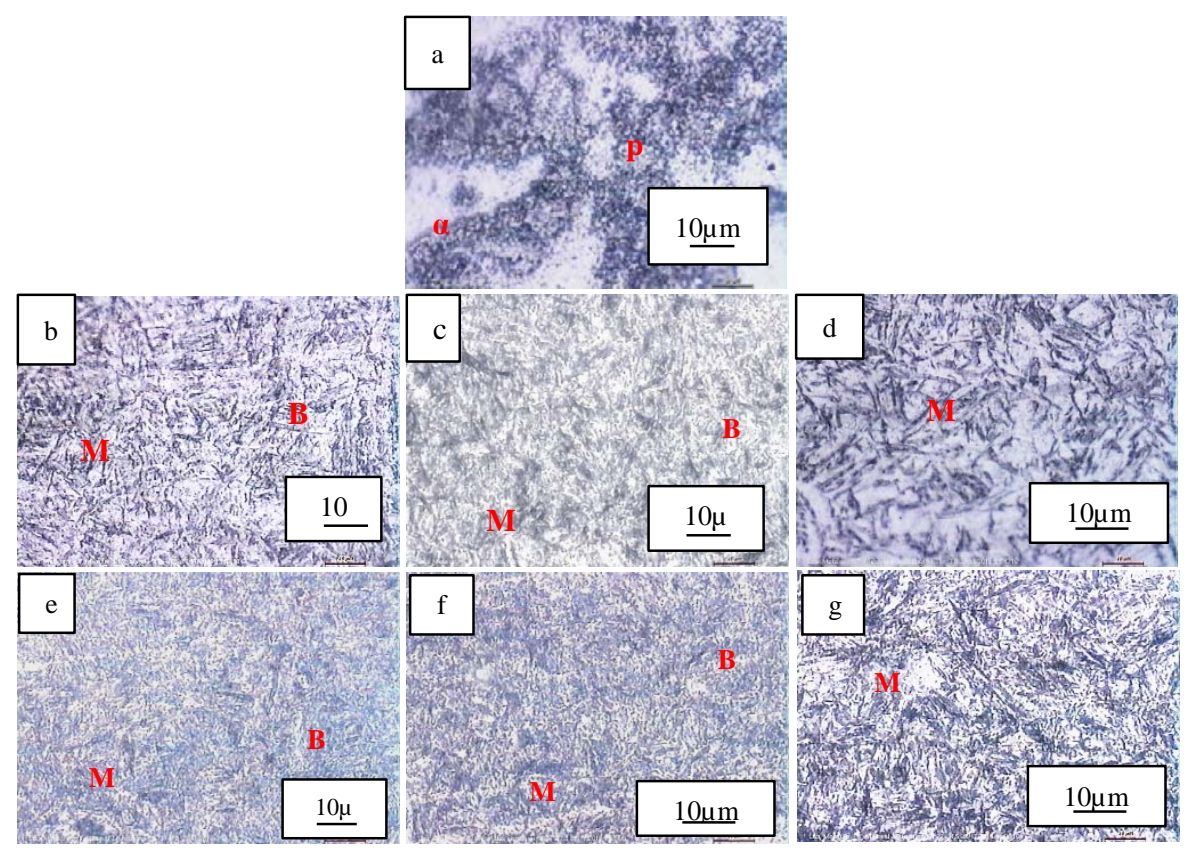

Figure 2. Light optical micrograph of specimens (a) AISI 8655 (b) AISI $8655 \mathrm{H850}{ }^{\circ} \mathrm{C}$-ht 30 min qm air (c) AISI $8655 \mathrm{H} 850^{\circ} \mathrm{C}$-ht 30 min qm oil (d)AISI $8655 \mathrm{H8} 50^{\circ} \mathrm{C}$-ht 30 min qm water (e) AISI8655 H850 $\mathrm{C}$-ht $60 \mathrm{~min}$ qm air (f) AISI $8655 \mathrm{H} 850^{\circ} \mathrm{C}$-ht 60 min qm oil and (g) AISI 8655 


\section{RESUlTS AND DISCUSSION}

\section{A. Metallography Analysis}

Micrograph of AISI 8655 and hardened AISI 8655 in heating temperature of 30 minutes and 60 minutes continued by cooling in air, oil and water medium are presented in Figure 2. Microstructures of AISI 8655 that shows in Figure 2a are coarse ferrite and pearlite. Based on chemical compositions and according to steel equilibrium phase transformation [1], the steel with 0,59 wt\% $C$ and low percentages of alloying element has ferrite and pearlite microstructures. Ferrite is seen by bright side and pearlite is seen by dark side. Figure $2 b$ and Figure 2c show microstructure of AISI 8655 which heated at $850^{\circ} \mathrm{C}$ then held for 30 minutes and cooled respectively by air and oil. Microstructures of the spesimens after cooling process are martensite and bainite. The type of martensite seen in the Figure $2 \mathrm{~b}$ and Figure 2c is plate martensite. The plate martensite is formed during non equilibrium transformatiom of medium carbon steel whereas AISI 8655 with $0.59 \% \mathrm{C}$ is classified as medium carbon steel.

Based on continous cooling transformation diagram [3], martensite and bainite are formed when low alloys steel was heated into austenite temperature then cooled in specific cooling rate. During cooling process, austenite achieves $B s$ tempereture then transforms to bainite until it achieves $B f$ temperature. Residual austenite achieves $M s$ tempereture then transforms to martensite until it achieves $M f$ temperature. Martensite and bainite structures are distributed uniformly. Figure 2d shows microstructure of AISI 8655 which heated at $850^{\circ} \mathrm{C}$ then held for 30 minutes and cooled by water. Microstructure results from hardening process is martensite. Full martensite is formed when low alloys steel is heated at austenite temperature then cooled rapidly until critical cooling rate reached [3]. Figure 2e and Figure 2f show microstructure of AISI 8655 which heated at $850^{\circ} \mathrm{C}$ then held for 60 minutes and cooled respectively by air and oil. Martensite and bainite are microstructure that formed by this processes. Figure $2 \mathrm{~g}$ shows martensite microstructure in AISI 8655 which heated at $850^{\circ} \mathrm{C}$ then held for 60 minutes and cooled by water.

\section{B. Hardness properties}

Figure 3 ilustrates hardness of AISI 8655 and hardened AISI 8655 in various holding time and quenching medium. The hardness values are also mentioned in Table 2 . According to the Figure 3, hardness of AISI 8655 increases significantly due to the hardening process. Holding time of 30 minutes gave higher final hardness than that of 60 minutes. Quenching medium also affects to hardness increacement of AISI 8655. Water as quenching medium performs higher hardness increasement than oil and air. Water which has higher grossmann factor value provides higher cooling rate if it is compared with oil and air. Air as rapid cooling medium contributes the lowest cooling rate among them so that hardness after this process lower than that of oil and water [3]. These final hardness correspond with microstructures in Figure 2. Specimens quenched by water have microstructure of martensite and consequenly have the highest final hardness. Specimens cooled by oil and air have martensite and bainite microstructures. In particular, bainite has lower hardness than that of martensite. Consequently, specimens cooled by oil and air have lower hardness than specimens cooled by water.

TABLE 2.

HARDNESS AND IMPACT STRENGTH OF HARDENED STEEL

\begin{tabular}{lcc}
\hline \hline Material & Hardness (BHN) & Impact Strength $\left(\mathbf{J} / \mathbf{m m}^{2}\right)$ \\
\hline AISI 8655 & 243 & 2.6 \\
AISI 8655 H850 $\mathrm{C}$-ht 30 min qm air & 520 & 2.0 \\
AISI 8655 H850 $\mathrm{C}$-ht 30 min qm oil & 540 & 2.1 \\
AISI 8655 H850 $\mathrm{C}$-ht 30 min qm water & 552 & 2.5 \\
AISI 8655 H850 $\mathrm{C}$-ht 60 min qm air & 491 & 2.8 \\
AISI 8655 H850 $\mathrm{C}$-ht 60 min qm oil & 518 & 3.8 \\
AISI 8655 H850 $\mathrm{C}$-ht 60 min qm water & 518 & 7.5 \\
\hline \hline
\end{tabular}

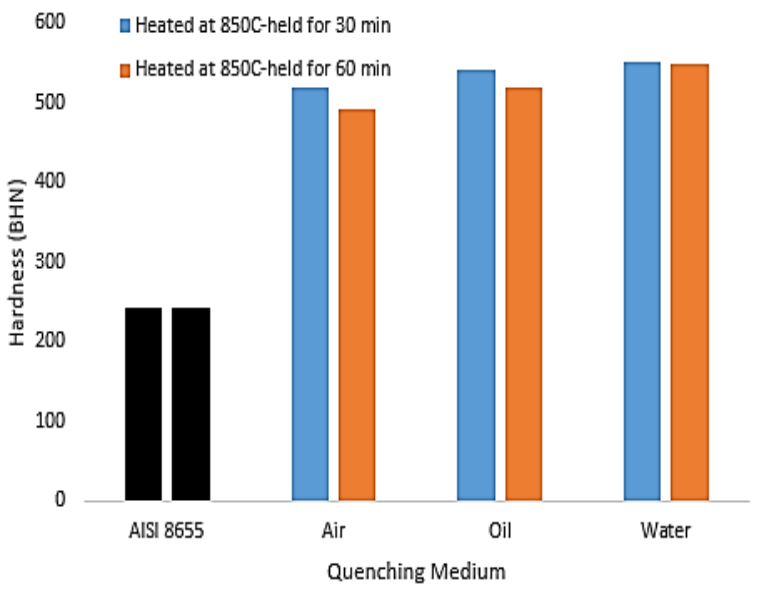

Figure. 3. Hardness of AISI 8655 after hardening process

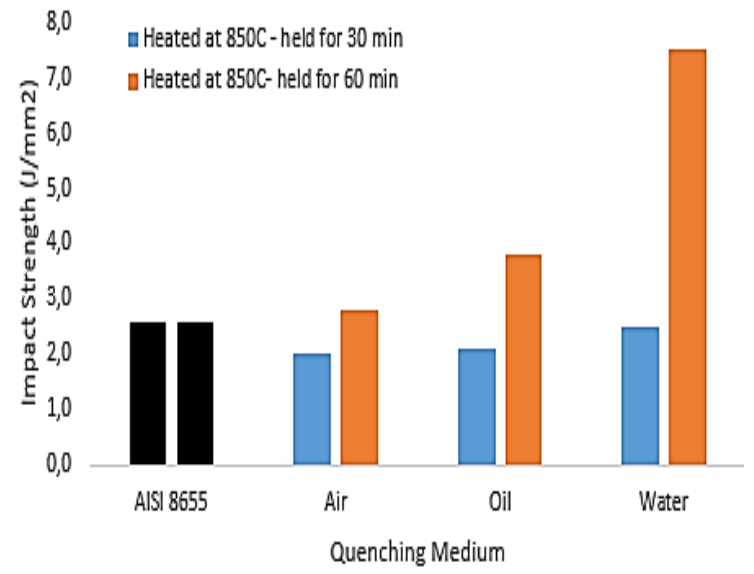

Figure. 4. Impact strength of AISI 8655 after hardening process 
Final harndess of steel after hardening process is affected by some factors (i) carbon content of steel, (ii)percentages of alloying element, (iii) austenite heating temperature, (iv) holding time, (v) quenching medium. The higher of steel carbon content, the higher martensite hardness after heat treatment. It affects the improvement of final hardness of steel. Alloying element can produce higher steel hardenability. Martensite and bainite as hard-phases of steel is formed from non equilibrium austenite transformation. Insufficient of heating temperature and holding time leaves ferrite that no able to transform into hard-phase. Performance of quenching medium was affected by its particles movement ability and its ability to heat absorption. Furthermore, they are converted to some fluid properties and condition such as viscocity, thermal conductivity, boiling temperature and agitation. Oil has higher boiling temperature than water but water has higher thermal conductivity and viscosity than oil so that water can produce higher cooling rate than oil and more martensite phase. Air has the lowest particle movement speed and heat absorption ability than both of oil and water because of a large distance among its particles [3]. All of these factors have to control in the aim to hardness improvement in steels.

\section{Impact strength}

Figure 4 presents room-temperature impact property of AISI 8655 and hardened AISI 8655 in various holding time and quenching medium. The impact values are also mentioned in Table 2. AISI 8655 that are held for 60 minutes has higher impact strength that AISI 8655 that are held for 30 minutes. Air as cooling medium produces lower final impact strength than oil and water. In holding time of 60 minutes, hardening processes not only improves hardness but also improves impact strength significanly.

\section{CONCLUSSON}

AISI 8655 which has ferrite and pearlite microstructures was successfully improved in hardness and impact properties by various hardening method in this work. AISI
8655 specimens, heated at $850^{\circ} \mathrm{C}$, held for 30 minutes and cooled by air, oli and water have hardness of $520 \mathrm{BHN}$, 540 BHN and 552 BHN. Specimens have impact strength of $2.0 \mathrm{~J} / \mathrm{mm}^{2}, 2.1 \mathrm{~J} / \mathrm{mm}^{2}$ and $2.5 \mathrm{~J} / \mathrm{mm}^{2}$. AISI 8655 specimens, heated at $850^{\circ} \mathrm{C}$, held for 60 minutes and cooled by air, oli and water have hardness of 491 BHN, $518 \mathrm{BHN}$ and $548 \mathrm{BHN}$. Specimens have impact strength of $2.8 \mathrm{~J} / \mathrm{mm}^{2}, 3.8 \mathrm{~J} / \mathrm{mm}^{2}$ and $7.5 \mathrm{~J} / \mathrm{mm}^{2}$. After hardening, microstructures of AISI 8655 convert to martensite and bainite.

\section{ACKNOWLEDGEMENTS}

The author gratefully acknowledges the people who have assisted and contributed to this research. Special mention for Department of Materials Engineering ITS which facilited some testing instrumets. This research was financially supported by KEMENRISTEKDIKTI and LPPM-ITS throuh "Penelitian Pemula".

\section{REFERENCES}

[1] S. H. Avner, Introduction to physical metallurgy, 2nd ed. New York: McGraw-Hill, 1974

[2] Y. P. P. Ramadhan, "Analisis kegagalan hammer crusher pada PT. X,” Surabaya, 2016.

[3] G. E. Totten, Steel heat treatment: metallurgy and technologies Hoboken: Taylor \& Francis, 2007.

[4] Z. Fatoni, "Pengaruh perlakuan panas terhadap sifat kekerasan baja paduan rendah untuk bahan pisau penyayat batang karet," $J$. DESIMINASI Teknol., vol. 4, no. 1, pp. 56-63, 2016.

[5] M. J. Santofimia, C. Kwakernaak, W. G. Sloof, L. Zhao, and J. Sietsma, "Experimental study of the distribution of alloying elements after the formation of epitaxial ferrite upon cooling in a low-carbon steel,” Mater. Charact., vol. 61, no. 10, pp. 937-942, Oct. 2010.

[6] B. H. Kim et al., "Effect of Ti addition on hardness change during tempering in reduced activation ferritic/martensitic (RAFM) steels,” J. Nucl. Mater., vol. 508, pp. 595-598, Sep. 2018. 